\author{
NINA PLUTA \\ Universidad Pedagógica de Cracovia \\ plutaster@gmail.com
}

\title{
EL NAZISMO A LA LUZ DE LAS NOVELAS HISPANOAMERICANAS ACTUALES
}

\begin{abstract}
Nina Pluta, El nazismo a la luz de las novelas hispanoamericanas actuales [Nazism in the light of recent spanish american novels], Studia Romanica Posnaniensia, Adam Mickiewicz University Press, Poznań, vol. XL/2: 2013, pp. 75-89. ISBN 978-83-232-2597-3. ISSN 0137-2475. eISSN 2084-4158.

The exchange of ideas and cultural influences between postcolonial countries of both Americas and the mother countries, has never been limited to one-sided imitation of European patterns. Since the XIX ${ }^{\text {th }}$ century or even since the colonial period, European theories rooted locally giving original fruits (i.e. magical realism, the Latin American version of world's primitivisme from the first half of the $\mathrm{XX}^{\text {th }}$ century). Within the broadly defined transatlantic studies, the particular aim of this paper is to explore motives related to fascism and nazism present in the modern Spanish American prose (Roberto Bolaño, Ignacio Padilla, Jorge Volpi). Firstly, I draw the cultural context in which racist and esoteric ideas of renewing the world infiltrated to Latin America. In the second part I analyse ways to adapt fascist plots in modern novels. Among them the predominating tendencies are to parody the totalitarian ideas or to see them as an incarnation of the intangible evil.
\end{abstract}

Keywords: nazism, Spanish American contemporary fiction, XX-XXI ${ }^{\text {th }}$ century novel, Roberto Bolaño

En algunas obras notables de la narrativa hispanoamericana reciente encontramos unas visiones de las grandes ideologías y de las sacudidas políticas europeas y mundiales del siglo XX: por ejemplo, en la así llamada trilogía del siglo XX del mexicano Jorge Volpi, integrada por En busca de Klingsor (1999), El fin de la locura (2003) y No será la tierra (2006), asimismo en la novela 2666 del chileno Roberto Bolaño (2004) o en la del cubano Leonardo Padura titulada El hombre que amaba a los per$\operatorname{ros}(2009)$.

Cabe notar que este tipo de temática global o transatlántica no es una novedad exclusiva del cruce de los siglos. En 1962, El siglo de las luces de Alejo Carpentier mostraba el ciclo de esplendor-miseria de las revoluciones. Terra nostra de Carlos Fuentes, de 1975, trazaba un fantástico destino común para Europa y las Américas. Es cierto que la tendencia, llamémosla cosmopolita, sin ser mayoritaria, siempre había sido perceptible en las letras hispanoamericanas; recordemos las palabras de Jorge Luis Borges: "mi patrimonio es el universo" (Borges, 1991). 
A partir de fines de los 60. los protagonistas de las ficciones latinoamericanas empezaron a recorrer el mundo con más frecuencia, por motivos políticos, pero no sólo por ellos (véanse, p. ej. las novelas del peruano Alfredo Bryce Echenique). Mientras tanto, se fue debilitando, para desmoronarse del todo, la longeva convicción de que la literatura, la hispanoamericana en particular, debe transmitir valores identitarios colectivos. De hecho, en las últimas décadas, la propia noción de identidad (cultural, nacional, colectiva) ha sido cuestionada en su esencialismo y suplantada por la transnacionalidad o, en palabras de Fernando Aínsa, en "lealtad múltiple". Debido a las migraciones, los desplazamientos físicos, mediáticos y virtuales, la cultura y literatura de Latinoamérica forma hoy "parte del pluralismo multipolar a través del cual se expresa el mundo contemporáneo, (se ha convertido en uno de) esos nuevos centros que genera la propia periferia" (2010).

Desde mediados de los 80, los autores hispanoamericanos han reivindicado una incondicional libertad en lo que toca, entre otros, a la ubicación geográfica de sus mundos ficcionales; con en fin de, en palabras de Rodrigo Fresán, "perder el adjetivo latinoamericano para quedarme en escritor a secas" (2004: 74). En efecto, hoy las tramas se ambientan en cualquier lugar del universo real o alternativo y los héroes no han de ser necesariamente latinos.

Alrededor del cruce de los siglos una serie de obras narrativas hispanoamericanas destacadas renueva el tema del nazismo. Se lo evoca y recrea como una época histórica, pero también se lo universaliza como una ideología funesta que ha influido de forma perenne en la memoria colectiva del Occidente y del mundo entero. El nazismo reaparece pues bajo la forma de una trama ambientada en los años auge de su desarrollo político (20.- 40. del siglo XX, p. ej. en En busca de Klingsor de Volpi), o bien como una ideología maligna que influyó en las mentes occidentales: desde la época de la gestación del fascismo y de otras concepciones que en las primeras décadas del siglo XX parecieron providenciales para salvar el mundo, hasta los diversos matices del ideario de la extrema derecha, en la segunda mitad del siglo.

¿Qué tiene de particular y eventualmente de reveladora la mirada, desde Latinoamérica, sobre el nazismo, es decir, uno de los exponentes mayores del terror político europeo del siglo XX? Tal vez no deberíamos hacer esta pregunta porque con ella recaemos en la óptica regionalista. Y a fin de cuentas, ¿por qué una narrativa latinoamericana sobre temas universales debería de antemano leerse como diferente? A eso contestamos con las palabras de uno de los autores comentados más adelante, Ignacio Padilla: "uno podía deslindarse de los localismos, pero no por ello se dejaba de hablar desde un sentido profundamente latinoamericano ni se renunciaba a escribir sobre América Latina" (2004: 142).

Hago primero un apartado sobre el nazismo histórico en América Latina, para pasar después a las reelaboraciones literarias.

El nazismo enlazó con las corrientes del pensamiento europeo del cruce de los siglos XIX y XX que habían encontrado acogida en Latinoamérica. Desde Spencer y el 
positivismo pasando por Nietzsche hasta el conde Keyserling y Osvald Spengler, las ideas de desarrollo orgánico, de evolución y de jerarquía racial fueron trabajadas por los intelectuales hispanoamericanos preocupados por las deficiencias económicas y sociales del continente (Alcides Arguedas, César Zumeta, Francisco Bulnes, José Ingenieros). Tanto los ensayistas como los científicos consideraron entonces oportuno exaltar la herencia de la civilización latina, incluida la ibérica, frente al pragmatismo y materialismo burdo de Estados Unidos (véase la conocida oposición de José Enrique Rodó entre Ariel y Calibán). Los descendientes de la civilización latina fueron pregonados como superiores gracias a su propensión a las cosas espirituales. Ya desde mediados del siglo XIX, los estados hispanoamericanos fomentaron las inmigraciones selectivas de europeos (Chile, de alemanes, Argentina, de alemanes e italianos), en el marco de sus políticas racistas, tratando de paliar de este modo el problema de la no integración y no participación de los grupos indios, mestizos y rurales, en la vida social. En el modernismo, a la superioridad de una raza sobre otras, se le añadió además una perspectiva escatológica. Un ejemplo: prolongando la inspiración de la biología social positivista, en un espíritu más mesiánico, el pensador y político mexicano José Vasconcelos fantasea en su conocido ensayo del 1925 sobre las virtudes de la supuesta quinta raza que iba a perfeccionarse en América Latina: la "cósmica", derivada del amalgama de las mejores cualidades que ofrecen las cuatro razas mundiales existentes (La raza cósmica, 1925).

En América, la cuestión racial fue adaptada a las circunstancias locales llevando o bien a unas conclusiones razonables, o bien a ideas cercanas al prejuicio. El boliviano Alcides Arguedas explicaba la inanidad de los indios de su país tanto por el agotamiento sistemático al que fue sometido este grupo, desde el siglo XVI, tanto por una disposición especial del espíritu, fruto del paisaje desolado del antiplano boliviano:

El aspecto físico de la llanura [...] ha moldeado el espíritu de manera extraña. Nótase en el hombre del altiplano la dureza de carácter, la aridez de sentimientos, la absoluta ausencia de afecciones estéticas. El ánimo no tiene fuerzas para nada, sino para fijarse con persistencia en el dolor. Llégase a una concepción siniestramente pesimista de la vida [...]. Tal es la ética que se desprende en una región así y entre hombres que han perdido lo mejor de sus cualidades (Arguedas, 1993: 2010).

En el enfoque de Arguedas no hay desprecio por una raza creada a priori como inferior; hay sin embargo una convicción de extremo pesimismo: en esas condiciones naturales y sociales (aguantando la presión de los curas, funcionarios y patrones), el indio no va a poder mejorar ni un ápice su situación. Otras consideraciones raciales hoy parecen más anacrónicas: Francisco Bulnes creía, por ejemplo, que la falta de progresos civilizatorios entre los indios de Mesoamérica se debía a la dieta basada en el maíz. "La humanidad, de acuerdo con una severa clasificación económica, debe dividirse en tres grandes razas: la raza del trigo, la raza del maíz y la del arroz. ¿Cuál de éstas es indiscutiblemente superior?" (1992: 17). Bulnes afirma que la raza del trigo es 
la única verdaderamente progresista y que "las razas que se alimentan exclusivamente de maíz y de arroz son casi desfosforadas, lo que explica su falta de potencia y su aspecto melancólico" (Bulnes, 1992: 20).

No es tal vez casual que algunos pensadores que ahondaron en las cuestiones de la raza, por ejemplo, Alcides Arguedas y José Vasconcelos, experimentaran luego una fascinación por el nazismo; el primero citó a Hitler como una autoridad en las cuestiones raciales (Oviedo, 2005), el segundo colaboró en el 1941 con una revista mexicana pronazi Timón. Entre los famosos intelectuales de la época, mordidos por el fascismo, cabe también citar al escritor argentino Leopoldo Lugones, quien desde los años 20. anuncia "la hora de la espada", el proyecto de una revolución autoritaria en contra del sistema democrático.

Las inquietudes respecto a las posibilidades de mejorar la raza, aunque en América se desviasen naturalmente hacia la cuestión de los indios y los negros, entroncan con reflexiones similares en los movimientos fascistas y nazistas en Europa. Es conocida la exaltación, por varios pensadores alemanes de comienzos del siglo XX, de la raza aria, la supuesta noble antecesora de los pueblos germánicos y nórdicos, la crema y nata de la humanidad. La tradición de esa raza fue supuestamente salvaguardada a través de los siglos por los magos, los templarios y algunos místicos cristianos. Estas inspiraciones se desarrollaron en los movimientos neopaganos (anticristianos) y pangermánicos, a finales del siglo XIX: Guido von List y la Orden de los Armanos; Joerg Lans von Liebenfels y "Ostara", La Orden de los Neotemplarios, y finalemente la Sociedad Thule (1918), que posteriormente se convirtió en el refuerzo político armado de la derecha radical, cercana a la Deutsche Arbeiterpartei, renominada después como NSDAP, cuyos miembros tomaron después una parte activa en el Putsch de Munich. Por sus rituales de iniciación secretos pasaron después, entre otros, Adolf Hitler, Hans Frank, Rudolf Hess y Alfred Rosenberg. El Instituto Anhenerbe, fundado en 1935, que pasó a formar parte de las SS, pregonó el misticismo de la sangre y la raza, fundiendo las teorías del darwinismo social con una seudoreligiosidad aria. En 1939 organizó una expedición científica al Tíbet para investigar el perfil antropológico de los últimos arios (King, 1996).

Es de notar que la reflexión sobre la raza corre, a principios del siglo, paralelamente a visiones de gran envergadura, sobre la necesaria renovación espiritual del mundo. De ella se iban a encargar unos grupos de personas superiores, dotadas de unos saberes secretos transmitidos a través de los siglos. Las organizaciones esotéricas como la Sociedad Teosófica (fundada en 1875 por Helena Blavatsky), la Ley de Thelema de Arnold Krumm Heller o las logias masónicas (la de Aleister Crowley), unían eclécticamente las múltiples tradiciones esotéricas mundiales: desde el budismo tántrico, pasando por la magia nórdica, rozacruz hasta el ritual masónico. En De sangre y sol el mexicano Sergio González Rodríguez sigue el rastro de los que a principios del siglo XX buscaron las fuentes primordiales de la vitalidad y la energías, olvidadas por el Occidente tecnologizado. El itinerario, a menudo, incluía 
a México, con sus cadenas montañosas y volcanes, ya que, según los esotéricos, los lugares secretos podían encontrarse en las partes elevadas del globo: el Tíbet, el Cáucaso. También las montañas americanas atraían a los espíritus inquietos de la época. Blavatsky viajó a México ya a mediados del siglo XIX, Krum Heller, quien además participó en la Revolución Mexicana, se interesó por los rituales sangrientos de los aztecas (González Rodríguez, 2008: 59-61). Artistas, como Antonin Artaud, procuraron experimentar en su propia piel las iniciaciones reveladoras de las tribus indígenas (en este caso, los tarahumaras). Es significativo que, al volver éste último de América, André Breton le dijera: "Sé que usted comprende cosas bellas. Creo que debemos hacer un fascismo a la mexicana" (cit. por González Rodríguez, 2008: 110).

El fascismo se percibía, con toda evidencia, como una doctrina purificadora y vitalista. Es cierto que no todos los que buscaban salvar el mundo activando los saberes ocultos se comprometieron con unas políticas que empañaban la pureza de sus ideas, pero en ocasiones hubo vinculaciones e intereses comunes, como, por ejemplo, en el caso de Karl Haushofer, cuyas concepciones de la geopolítica alemana reclamaban un espacio vital para los descendientes de los arios y la protección armada de su territorio.

El ya citado mexicano Vasconcelos se muestra inquieto en Indología (1929) por el materialismo y la brutalidad de las políticas hispanoamericanas de su época, pero mantiene una fe firme en el advenimiento de la renovación:

La tenacidad con que en determinados sitios el esfuerzo se mantiene inflexible nos da derecho a concebir esperanzas. Así como hay tantos que todo lo fían al azar y al cinismo, hay también otros que logran poner en acción las fuerzas superiores de la vida. Hay no sé qué vago idealismo, no sé qué misticismo confuso, pero profundo, como un cristianismo que se renueva libre y fervoroso. Tarde o temprano triunfa el bien. Lo que a mí todavía no me descubre la Historia es la manera del triunfo. No sé si el triunfo y la liberación son casos individuales, como lo afirma el saber tradicional, o si no estamos totalmente errados los que creímos, con todo el idealismo social del siglo XIX, que el progreso podía adoptar formas universales y colectivas para que la salvación ya no se hiciese por individuos, sino por pueblos. El enigma sigue insoluble. Prestemos nuestro aliento al soplo de la esperanza, ya que así lo manda la ley de emoción de esa filosofía que yo quiero ver brotar en el continente (Vasconcelos, 1993: 343; subrayado mío).

Una decena de años más tarde, se despejará el enigma sobre "la forma colectiva de la salvación", y Vasconcelos escribe en Timón:

Lo que si va apareciendo evidente, aun para los empecinados, es el triunfo de Alemania sobre sus rivales y el cambio histórico que en consecuencia va a operarse en el mundo... ¡Pero ganaremos con la victoria alemana! Y no porque creamos que Alemania va a constituirse en campeón de Latinoamérica. Es ley de la Historia que cada pueblo conquiste su propia libertad... (cit. por Bar-Lewaw, 1971: 155).

El nazismo, sin embargo, convertirá las inspiraciones pospositivistas y mesiánicas en la razón de una política totalitaria y de exterminio. En la misma época, en los 
años 20 y 30, los círculos de derechas y nacionalistas latinoamericanos tendían, en su mayoría, al militarismo'. De este modo, cuando los políticos de la Alemania de Hitler quisieron, a partir de 1933, extender su influencia también a América Latina, encontraron una "tradición autoritaria local proclive a este tipo de pensamiento" entre los conservadores, los militares, algunos grupos profesionales y de la juventud militante (Gaitán-Bohórquez y Malagón-Pinzón, 2009: 297). La concepción fascista de un estado construido con base en el corporacionismo, catolicismo y pureza racial fue promovida tanto en Colombia, donde la derecha reaccionó al gobierno liberal de López Pumarejo, como en Brasil, por la Acción Integralista Brasileña a fines de los 30., o como luego en Argentina durante el peronismo de los años 40. y 50. (Gaitán-Bohórquez y Malagón-Pinzón, 2009: 297).

Antes de la II Guerra Mundial, en los 30., fue patente la colaboración entre los militares y los diplomáticos chilenos con los servicios nazis. El partido nacionalsocialista chileno fue aprobado desde Berlín en 1932. Posteriormente, el Instituto Iberoamericano, con el general Wilhelm Faupel a la cabeza, propagó la causa nazi entre los militares chilenos. El joven Augusto Pinochet, por ejemplo, usaba para los cursos de formación militar que impartía una revista editada en el espíritu nacionalsocialista titulada "Ejército-Marina-Aviación". Se fomentó la colaboración entre los cuerpos médicos de Alemania y los países latinoamericanos a través de la Academia Médica Ibero-Americana (DIAÄ) creada en 1935, que recibió a unos 600 médicos de América Latina (Farías, 2000 : 355).

Muchos de los conservadores latinoamericanos simpatizaron durante la II Guerra Mundial con los países del eje, aunque al terminar el conflicto, se recondujeron hacia el franquismo, una opción menos compremetedora y más tradicional. A su vez, los aliados dieron su aprobación tácita a que varios exiliados alemanes, entre ellos los criminales nazis, encontrasen refugio en Argentina y otros países como Uruguay, Chile o Brasil. Los científicos alemanes se dispersaron entonces por el mundo, y varios entre ellos fueron, a pesar de su anterior colaboración con el nazismo, acaparados secretamente por los gobiernos de la URSS, los Estados Unidos y Gran Bretaña (de Nápoli, 2008: 13-18).

Se conformó una nueva geopolítica durante la guerra fría, y, siguiendo sus pautas, los ultraconservadores hispanoamericanos pasaron de la animadversión hacia Estados Unidos, dominante en la época arielista, a un apoyo fervoroso al vecino del Norte, líder de la caza al comunismo. En la segunda mitad del siglo XX, las dictaduras latinoamericanas se convierten en "una prolongación, en un ritmo de 'baja pero prolongada intensidad', del enfrentamiento que entre el comunismo y las derechas

${ }^{1}$ Como opina Halperin Donghi, “antes de entrar en crisis el orden neocolonial, el proceso de la democratización política, de avance muy desigual en en Latinoamérica, aparece amenazado por la rivalidad de soluciones revolucionarias y la más seria de otras autoritarias" (Halperin Donghi, 2005: 299). 
europeas se había saldado en Yalta" (Gaitán-Bohórquez y Malagón-Pinzón, 2009: 297-313). Las dictaduras mencionadas ni se declaraban ellas mismas fascistas ni son unánimamente calificadas por los historiadores como tales. Por otro lado, consta que algunos nazis refugiados colaboraron con los artífices de las dictaduras chilena y argentina. De todos modos, en la percepción de sus oponentes, los gobiernos militares latinoamericanos podían ser equiparados con el fascismo y el nazismo en lo que Farías (2000: 10) afirma como definitorio de éste último, a saber, la inhumanidad de los métodos de persecusión y de exterminio en nombre de una higiene social monstruosa. Los procederes de los servicios secretos y de seguridad de las dictaduras hicieron pues pensar, como en el caso del nazismo, en una "patología sicológica extrema" y en "un espectáculo metafísico desfiante" (Farías, 2000: 11), donde el mal se convertía en el principio del universo humano. En este sentido los militares argentinos o chilenos sí eran "fascistas" o "nazis" a los ojos de muchos de sus contemporáneos.

En las obras de Roberto Bolaño (Chile, 1950-2003), el nazismo resurge, en primer lugar, como una sombra que planea sobre las acciones represivas de las dictaduras militares (por ejemplo, en Estrella distante, 1999); en segundo, en un sentido más amplio, como una ideología que se impone en la mentalidad europea y amenza a la libertad intelectual y artística en la primera mitad del siglo XX (la novela 2666 de 2004); en tercero, en la paródica obra La literatura nazi en América (1996), dicha ideología funge como fuente de inspiración para las ideas más disparatadas sobre la regeneración de la civilización occidental y americana².

En Estrella distante el fascismo constituye una inspiración para los crímenes cometidos en nombre de unos ideales más altos: fe inquebrantable, hombre superior, salvación del género humano. El protagonista que los profesa, Alberto Ruiz-Tagle, alias Carlos Wieder, es agente secreto en el Chile pinochetista. Se infiltra en los medios estudiantiles y de cultura alternativa, causando muertes y desapariciones. El narrador, un observador-testigo, da a entender que a Wieder lo mueve, a nivel personal, la ambición literaria y el deseo de dominación; a nivel político comparte con sus mandatarios, los militares, la aprobación de la violencia brutal y la determinación "neonazi" de eliminar a los opositores políticos como unas ratas. Carlos Wieder es, sin embargo, un personaje complejo, inteligente, con ínfulas de misterioso, sensible a la belleza. Crea en los testigos la impresión de que sus performances artísticas, tales como los poemas escritos con el humo del avión, conllevan algo de compromiso sincero. Y esto precisamente se convierte en el punto ciego, el vórtice del misterio que Bolaño nos pone, insistentemente, ante los ojos en varias obras suyas: la posibilidad de aunar el arte — aquí una especie de posvanguardia permeada

${ }^{2}$ Otra novela del autor donde se hace notar el influjo latente del fascismo y del nazismo es Monsieur Pain, 1999. 
de violencia - y la vileza, el instinto criminal. No sin razón el ensayo donde uno de los testigos intenta explicar el fenómeno de Wieder, se titula "La exploración de los límites" (Bolaño, 2000: 117). En esos límites borrosos, la figura del que quiso destilar poesía de los cuerpos de mujeres y hombres torturados permanece impenetrable. La novela remite implícitamente al irracionalismo y ocultismo que emana de los escritos y los discursos de Hitler y otros ideólogos del nazismo como Rosenberg o Himmler.

2666, novela póstuma de Bolaño, imponente con su volumen de más de 1100 páginas, crea un efecto de totalidad. Caben en ella tanto las pesquisas sobre los crímenes de las mujeres de Ciudad Juárez en México, de fines del siglo XX, como las peripecias de cuatro investigadores literarios europeos, como también, en la quinta parte, una visión personalísima del nazismo y la II Guerra Mundial descrita desde la perspectiva de un insólito soldado alemán.

Por falta de tiempo nos centramos en este último hilo narrativo. A Hans Reiter lo vemos nacer en los años 20. en una aldea de la costa báltica alemana. Su excentricidad se anuncia desde el comienzo: "[N]o parecía un niño sino un alga" (Bolaño, 2004: 797). Lo atrae el agua y el mar, donde es capaz de permanecer más tiempo que otros mortales. La visión de la Alemania nazi no es desde luego la propia de una novela histórica. Ni la familia de Hans ni él mismo manifiestan el patriotismo esperado. Parecen anacrónicamente "postmodernos", de vuelta de todas las ideologías. En el desarrollo de la historia, Hans, aunque alemán, irá demostrando más bien su afinidad con la estirpe de los nómadas latinoamericanos del siglo XX que se conocen de otras obras bolañescas. Hans participa en la ofensiva de 1939 en Europa y luego en la campaña de Rusia, pero sigue siendo el sonámbulo, el que mira de otra manera. Su patrono es Parsifal, héroe de uno de los contados libros que Hans haya leído en su vida: "Parsifal en ocasiones cabalgaba (mi estilo es la profesión del escudo) llevando bajo su armadura su vestimenta de loco" (Bolaño, 2004: 823). En la Alemania de posguerra, Hans se convertirá en un misterioso escritor de culto, Arcimboldi, quien, para el colmo y de acuerdo con la lógica narrativa alucinatoria de Bolaño, va a parar en los años 90 en México y será acusado de cómplice en los asesinatos de las mujeres de Ciudad Juárez (Santa Teresa, en la novela).

La guerra, el nazismo, el totalitarismo soviético crean pues aquí un fondo histórico para un tema contemporáneo universal: la vocación literaria. Hans nace como escritor (sin saber todavía que lo será) a través del diario de Boris Abramovich Ansky, encontrado en una aldea desierta a las orillas del Dnieper. Las peripecias de este judío, aspirante a escritor y prófugo del ejército soviético, que había sobrevivido a las purgas estalinistas, le inspiran sentimientos totalmente nuevos. Hans descubre la libertad espiritual y "fuerzas para prolongar ese impulso de libertad, de soberanía hasta donde fuera posible" (Bolaño, 2004: 925). Adquiere una madurez en el discernimento entre las apariencias y otros valores realmente vitales: "El nacionalsocialismo era el reino absoluto de la apariencia. Amar, reflexionó, por regla 
general es otra apariencia. Mi amor por Lotte no es una apariencia. Lotte es mi hermana y es pequeña y cree que soy un gigante" (Bolaño, 2004: 926). Identificándose con Ansky siente "algo muy extraño y que a veces se parecía a la felicidad y otras veces a una culpa vasta como el cielo" (Bolaño, 2004: 926). En medio del caos y la degradación asimila la experiencia de otro y la convierte en estímulo, herencia, fidelidad, felicidad, deseo. Nace un escritor y retoma la tradición de Parsifal, el mito germánico, tan favorecido, por otro lado, en la cultura oficial nazista, pero que aquí queda reinterpretado como el mito del poeta-soldado o escritor-soldado, en la veta de Cervantes, otro patrono artístico de Bolaño.

El tema global de la rizomática novela se insinúa aquí con claridad. Son las relaciones entre la literatura y el mal, en otras palabras, el conflicto entre lo que se entiende como una literatura valiente y honrada y lo que, por otra parte, pervierte esa vocación: las ideologías dañinas, las represiones políticas, las ambiciones, la vileza, las humillaciones, las pequeñas renuncias privadas etcétera.

En otro libro de Bolaño, La literatura nazi en América (1996, cronológicamente el más temprano con los motivos en cuestión ${ }^{3}$ ), el fascismo sigue siendo algo como el polo de una atracción ideológica maligna, pero la magistral ironía, así como el tono de crítica literaria paródica, aligeran la seriedad del tema. Es una colección de biografías ficticias (a la manera del ensayo-ficción de Borges), reunidas en un extraño lexicón que, la fantasía mediando, remite a las posiciones ideológicas reales de aquellos intelectuales latinoamericanos del siglo XX que se dejaron seducir por el militarismo purificador: desde la exaltación de las fans americanas de Hitler en los años 30 hasta los poetas erráticos y trasnochados de los 70, que incorporan en sus obras la parafernalia místico-militar. Con ingenio y crueldad, Bolaño convierte en irrisión los numerosos matices de las ideologías de ultraderecha y del nacionalismo hispanoamericano, mostrándonos a sus epígonos en un espejo deformador (hay también algunas incursiones a la América del Norte). Las decenas de autores y sus obras respectivas analizadas con gran conocimiento de causa y rigor crítico $^{4}$ son de segunda o tercera fila, pero es en los escritores oscuros y marginales donde las ideas más influyentes y más contaminantes de una época determinada se deforman peligrosamente. Aquí, en concreto, se trata de las ideas, que circulaban en el siglo $\mathrm{XX}$, sobre la pureza de la sangre, la necesaria redención del universo por una raza superior o la excelencia del vigor físico y la disciplina militar.

Por otro lado, y Bolaño, quien fue un desconocido la mayor parte de su vida, lo sabe muy bien, desde el margen es más fácil adoptar una perspectiva oblicua y desmitificadora sobre lo más apetecible en el mercado de las ideas.

3 Aquí citamos la edición de Anagrama, de 2005.

4 Hablar sobre literatura es también literatura para los filósofos del posmodernismo, quienes han señalado y asumido abiertamente la dimensión retórica del discurso utilizado en las ciencias humanas. 
Uno de los biografiados por Bolaño, un tal Argentino Schiaffino, apodado El Grasa, es una eminencia gris en las así llamadas "barras bravas" (grupos de hinchas fanáticos) del equipo bonaerense Boca. Escribe poesía desde la edad de trece años. En los volúmenes que publica por su propia cuenta predominan dos temas significativos: el fútbol - El Espectáculo en el Cielo son "poemas cortos, ligeros, diríase alados sobre algunos de los grandes jugadores de la historia del Boca Juniors" (Bolaño, 2005: 175) - y un confuso militarismo. Publica, entre otros, "La invasión de Chile, en donde narra en clave de humor negro (en ocasiones parece el guión de una película gore) una supuesta guerra entre ambas repúblicas" (Bolaño, 2005: 173). Otro volumen suyo se titula La juventud de Hierro y contiene "poemas espesos o marchas militares cuya única virtud consiste en alejarle por primera vez de su marco expresivo natural: el fútbol y el humor" (Bolaño, 2005: 174).

En la recreación de la vida de Schiaffino, ni una mención explícita del nazismo. Pero el lector tiene en mente el título del lexicón bolañesco y asocia naturalmente los temas militares en la poesía de Schiaffino, su actuación violenta entre los hinchas (que llegan incluso a matar) con una observación, hecha como de pasada, una mera conjetura biográfica: "Se dice, también, que durante estos años participa activamente en el escuadrón de la muerte del capitán Antonio Lacouture, en calidad de conductor y mecánico del pequeño parque de coches que poseía este en una quinta en las afueras de Buenos Aires, pero no hay constancia" (Bolaño, 2005: 176).

De ahí, no se puede deducir, sin más, que para Bolaño todo hincha, argentino u otro, es un potencial simpatizante del nazismo. Lo que sí se puede, es observar, cómo de una idea a otra, de una afinidad a otra, pueden configurarse unos mapas mentales parecidos. El espíritu de afiliación seudomilitar de los hinchas, o de otros grupos que apuestan por la camaradería viril y la exaltación patriótica, puede llevar a aceptar la violencia como un medio legítimo de poder.

En otros retratos de los oscuros escritores, encontramos más ideas seudonazis deformadas y grotescas en su aplicación latinoamericana: y así, Franz Zwickau, venezolano de procedencia alemana, poeta maldito, muerto joven en los 70., se relaciona con unas organizaciones de nombres tan inverosímiles como "Mestizos Puros" o "Comuna Aria Naturalista". Max Mirebalais (nacido en 1941 en Puerto Príncipe), un plagiario perfecto, "cantaba la magnificencia de la raza aria y de la raza masai a partes iguales" (Bolaño, 2005: 140). "Ser un poeta nazi y no renunciar a cierto tipo de negritud pareció entusiasmar a Mirebalais" (Bolaño, 2005: 140).

En la América de Bolaño reaparece también la simbología neopagana. Pedro González Carrera, un humilde maestro chileno, que padece de alucinaciones e introduce en sus versos, "exactos y límpidos", los ejércitos del Duce y unos personajes armados ("merovingios de otro planeta") adorna uno de sus volúmenes con la palabra "doce": sus cuatro letras tienen "garras de águila en la parte inferior (y) se sujetan de una cruz gamada en llamas" (Bolaño, 2005: 75). Otro ejemplo de adaptación disparatada de las inspiraciones nazis: un joven educado en una colonia alemana en Chile 
(son inevitables las asociaciones con la colonia Dignidad) ${ }^{5}$, retraído y medio afásico, crea unos garabatos que son interpretados por los críticos como eminentemente vanguardistas: las líneas de sus versos serían como las alambradas de un campo de concentración.

En cuanto a las reformas que habrían de llevar al renacer de las Américas, Silvio Salvático (Argentina, 1901-1994) imagina varias de ellas:

Entre sus propuestas juveniles se cuenta la reinstauración de la Inquisición, los castigos corporales públicos, la guerra permanente ya sea contra los chilenos o contra los paraguayos o bolivianos como una forma de gimnasia nacional, la poligamia masculina, el exterminio de los indios para evitar una mayor contaminación de la raza argentina, el recorte de los derechos de los ciudadanos de origen judío, la emigración masiva procedente de los países escandinavos para aclarar progresivamente la epidermis nacional oscurecida después de años de promiscuidad hispano-indígena (Bolaño, 2005: 57).

Bolaño satiriza asimismo una disposición síquica entre los admiradores de las ideologías autoritarias: la de plegarse con deleite ante la autoridad y el carisma de los caudillos. La argentina Luz Mendiluce Tomphson, "conocida poetisa de ultraderecha", guarda por ejemplo, como su más valioso recuerdo de la infancia, una foto donde Hitler la lleva en brazos. Apócrifa o no, al parecer la foto encarna para ella el bienestar y la seguridad, emociones tan comunes que surgen en la cercanía del poder. "Y a veces reconocía sin ambages que [...] Hitler la había acunado y que aún, en los sueños, podía sentir sus brazos fuertes y el aliento cálido por encima de su cabeza" (Bolaño, 2005: 30). (En los años 70, la cruel ironía de la historia llevará a Luz a enamorarse de una joven militante de las izquierdas, la cual será asesinada por los militares).

Además de captar el vaivén de las ideas racistas y mesiánicas que circulaban entre Europa y América, el libro critica, con ingenio y fabulación desbordada, el funcionamiento de la vida literaria e intelectual en América Latina entre los años 30. y los fines del siglo $\mathrm{XX}^{6}$. La mordida fascista hizo a muchos transitar por el borde de un precipicio donde bullían ambiciones, sueños de regeneración y sentimentalismos disfrazados de recia masculinidad. "El texto comienza como un mero catálogo de fantasías librescas y culmina en una aterradora alegoría de la historia política y de la actividad literaria como una sola abominable experiencia" (Oviedo, 2005). Como en las obras antes comentadas (la última biografía de La literaura nazi... es el germen de Estrella distante, novela antes comentada), se evidencia el leitmotiv de la narrativa bolañesca: la literatura como actividad peligrosa; el riesgo de ser traicionado o de tracionar a los demás con la palabra altisonante. Una escena provocativa y simbólica del destino

${ }^{5}$ Colonia de alemanes en Chile, de funesta fama; hoy se reconoce que fue una secta, utilizada, entre otros, como centro de detención de presos bajo la dictadura.

6 "Lo que pasa es que yo cojo el mundo de la ultraderecha, pero muchas veces, en realidad, de lo que estoy hablando es de la izquierda. Cojo la imagen más fácil de ser caricaturizada para hablar de otra cosa. Cuando hablo de los escritores nazis de América, en realidad estoy hablando del mundo a veces heroico, y muchas más veces canalla, de la literatura en general" ("Entrevista a Bolaño", Lateral. Revista de cultura 40, abril, 1998). 
incierto de las obras literarias procede de la biografía de Edelmira Tomphson Mendiluce: durante su visita a la Alemania nazi, ella ofrece a Hitler un ejemplar de Martín Fierro de José Hernández, un poema épico del canon argentino. "Hitler agradece calurosamente obligándola a improvisar una traducción al alemán allí mismo, cosa que no sin dificultad consiguen entre Edelmira y Carozzone. Hitler se muestra complacido. Son versos rotundos y que apuntan al futuro" (Bolaño, 2005: 16).

Pasando a otros autores: los mexicanos Jorge Volpi, con la novela En busca de Klingsor de 1999, e Ignacio Padilla con Amphitryon, de 2000, aportan sendas variaciones narrativas sobre las Guerras Mundiales del siglo XX, el militarismo y el nazismo. Sus obras, a diferencia de las de Bolaño, prescinden de las referencias a América Latina. Estos autores se dieron a conocer a mediados de los 90 como integrantes de un grupo llamado crack, que postuló una literatura exigente y desvinculada de las servidumbres temáticas. La novela de Volpi es una historia seudocriminal, donde misterios malignos y motivos de espionaje se convierten en pretexto para reflexionar sobre el conocimiento, el mal y la identidad. La trama está ambientada en la primera mitad del siglo XX. El conflicto principal enfrenta a los científicos de Estados Unidos y Alemania en la carrera hacia la bomba atómica. La novela se centra en la persecusión del supuesto consejero científico del Tercer Reich, apodado Klingsor. Nótese que Klingsor es, en la historia medieval y en el drama de Wagner, el nombre del personaje que encarna el mal, oponiéndose al rey Amfortas y a Parsifal, el caballero del Graal. Encontramos pues otra referencia a Parsifal, héroe mitológico que exaltaron los nazis. Hay además, en la novela, entretenidas incursiones en las teorías matemáticas y físicas más influyentes del siglo XX y retratos costumbristas de las luminarias de las ciencias: Heisenberg, Einstein, Von Neumann, Planck, etcétera ${ }^{7}$.

El principio de incertidumbre (elaborado en la física por Werner Heisenberg), sirve aquí de enlace entre la problemática científica, la intriga de espionaje y las divagaciones existenciales y estéticas. Se convierte en la metáfora del azar que a menudo inhabilita los esfuerzos humanos de imponer orden y comprender el universo. Se opone igualmente, en su sentido más amplio, a la idea de que haya constancia y responsabilidad moral en nuestras decisiones. Los protagonistas parten de la física para meditar sobre la voluntad, el fracaso y el mal esencial que permea sin tregua la historia de la humanidad.

Algunos científicos, animados por la ambición, llegan a vender su talento y su alma. "No puedo creerlo", dice uno de los personajes a propósito de los que trabajaban bajo el régimen de Hitler en los proyectos atómicos, "No les importaban las vidas que iban a perderse con tal de ganar su carrera científica, con tal de demostrar que eran mejores que sus rivales... Me parece una actitud mucho más repugnante que la de Hitler" (Volpi, 2000: 280).

${ }^{7}$ Volpi hace un guiño a la tradición de la novela filosófica del siglo XVIII, titulando sus retratos de personajes famosos de forma alegórica, p. ej. "Johannes Stark, o de la infamia", "Erwin Schroedinger, o del deseo". 
A pesar de la multitud de datos, no es una recreación histórica, ni un enjuiciamento del fascismo. Más bien, tenemos que ver aquí con una reflexión universalista en la línea de Borges. El motivo de los nazis funciona como una lente de aumento de las crisis, las contradicciones y de los nuevos rumbos que se disponía a tomar el pensamiento occidental en el siglo XX (entre otros, el de la ruptura definitiva con el racionalismo tradicional, con las pretensiones totalitarias de las matemáticas, con el humanismo progresista).

A su vez, en la novela Amphitryon (2000), Padilla sitúa la historia en una extensión espacio-temporal que abarca varios lugares de Europa Central entre 1917 y 1989. Se acumulan en la trama motivos envolventes, tomados en préstamo del thriller y las novelas de espionaje, pero las experiencias de los protagonistas giran en torno a los dilemas existenciales. Uno de los hilos centrales es la puesta en marcha de un proyecto secreto en la cúpula del poder nazi, consistente en suplantar en ocasiones de riesgo a los altos mandos militares y políticos por sus dobles. Las secuelas de las sustituciones se prolongan en series de actos criminales hasta la segunda mitad del siglo XX, época desde la cual un narrador contemporáneo relata sus esfuerzos por desentrañar el turbio asunto. La intriga abunda en muertes misteriosas $\mathrm{y}$ trueques de personalidad que convierten la historia de espionaje en una suerte de espectáculo alegórico, donde el sentido figurado es la identidad, cuestión que inquieta a todos los personajes. Padilla hace a sus protagonistas luchar con el azar, sólo que no con el arma científica (como pasaba en la novela de Volpi), sino a través de actos más bien fantásticos, como la construcción de identidades sobre medida. La inapresabilidad de los criminales y los cambios de identidad crean un malestar intelectual y moral (los artífices del complot nazi, quienes parecen continuar sus maniobras criminales en el presente, no quedan descubiertos). Las guerras son un pretexto para desarrollar narrativamente el motivo de la incertidumbre, la orfandad y la obsesión por apresar al ser oculto que mueve las fichas. Los horrores de las contiendas mundiales se perciben como unas jugadas imprevisibles del ser supremo oculto. ¿Hay un destino? ¿o bien sólo existe el azar, que es su reverso? Emergen cuestiones propias para el pensamiento posmodernista y asimismo una reflexión sobre la ubicuidad del mal, institucionalizado y avalado por la aquiescencia tácita de todos. Si Volpi exploraba esa veta potenciando el efecto de realidad, Padilla tiende más hacia un thriller fantástico en blanco y negro.

\section{CONCLUSIONES}

En primer lugar, las elaboraciones ficcionales citadas utilizan el tema del fascismo y del nazismo para poner de relieve la profunda desazón, signo de nuestra contemporaneidad. Los racionalismos y humanismos han cedido paso a la ambigüedad y la incertidumbre. 
Para Bolaño, además, el nazismo es un símbolo del mal político e ideológico que acecha en la vida de varios personajes suyos; un mal que brota en varios puntos del globo a lo largo del siglo XX, prolongando más o menos directamente el impulso del nazismo histórico. Sobre todo, este autor trata del campo literario, donde la complicidad con la ideología nazi y otras afines ha llevado a menudo a la degradación moral e intelectual. Y el resultado artístico de la exaltación de la fuerza suele ser rídiculo y patético.

Es curioso que tanto en 2666 de Bolaño, como en el Klingsor de Volpi se aluda al mito germánico de Parsifal. Bolaño lo convierte en el emblema de los literatos nómadas, fracasados, malditos y deliberadamente automarginados de la sociedad global. Volpi lo actualiza, a su vez, como una suerte de reflejo (o puesta en abismo) de la intriga de su novela en la que se efectúa la lucha del bien con el mal; y su resultado es la incertidumbre.

Las obras examinadas universalizan notablemente las experiencias individuales de los protagonistas con el nazismo y la guerra. Se podría decir provisoriamente que el recurso a los nazis y al nazismo sirve en todos los casos no tanto para revelar/descubrir una parcela inédita de la historia mundial, sino, más bien, para generalizar la experiencia humana con la incertidumbre y con el mal disfrazado de ideología triunfante, por encima de los continentes. Una excepción a esta tendencia sería La literatura nazi en América de Bolaño, que insiste tanto en la difusión universal de las ideas fascistas y nazis, como en el peculiar "sabor latino" que adquieren aculturándose en un nuevo continente.

\section{BIBLIOGRAFÍA}

AínsA, Fernando (2010): "Discurso identitario y discurso literario en América Latina". Amerika. Mémoires, identités, territoires 1/2010: URL: <http://amerika.revues.org/478> (consultado el 20.09.2012).

Arguedas, Alcides (1993): “Pueblo enfermo". In: Leopoldo Zea [ed.], Fuentes de la cultura latinoamericana, t. II. México: FCE, 206-218.

BAR-LewaW, Itzhak (1971): “La revista «Timón» y la colaboración nazi de José Vasconcelos". In: AIH, Actas IV, <http://cvc.cervantes.es/literatura/aih/pdf/04/aih_04_1_018.pdf> (consultado el 20.01.2013).

Bolaño, Roberto (1998): “Entrevista a Bolaño” por Mihály Dés. Lateral. Revista de cultura 40. URL: <http://eljineteinsomne2.blogspot.com/2010/07/roberto-bolano-los-cubanos-eran.html> (consultado el 12 .01.2013).

— (2000): Estrella distante [1996]. Barcelona: Anagrama.

- (2004): 2666. Barcelona: Anagrama.

- (2005): La literatura nazi en América. Barcelona: Anagrama.

Borges, Jorge Luis (1991): "El escritor argentino y la tradición" [1953]. In: Discusión. Madrid: Alianza Editorial.

Bulnes, Francisco (1992): El porvenir de las naciones hispanoamericanas. México: Grijalbo.

FARÍAS, Víctor (2000): Los nazis en Chile. Barcelona: Seix Barral. 
FRESÁN, Rodrigo (2004): “Apuntes (y algunas notas al pie) para una teoría del estigma: páginas sueltas del posible diario de un casi ex joven escritor sudamericano". In: Palabra de América, Guillermo Cabrera Infante (intr.). Barcelona: Seix Barral, 47-74.

Gaitán Bohórquez, Miguel Alejandro; Malagón-Pinzón, Julio (2009): "Fascismo y autoritarismo en Colombia". Vniversitas, 118: 293-316. URL: <http://www.javeriana.edu.co/juridicas/pub_ rev/documents/12-Fascismoyautoritarismo_000.pdf $>$ (consultado el 10.09.2012).

GonzÁlez Rodríguez, Sergio (2008): De sangre y de sol. Barcelona: Editorial Sexto Piso.

Halperin Donghi, Tulio (2005): Historia contemporánea de América Latina. Madrid: Alianza Editorial.

KING, Francis (1996): Szatan i swastyka: okultyzm w partii nazistowskiej. Poznań: Axis, trad. al polaco de Jerzy Moderski y Tomasz Olszewski.

NÁPolı de, Carlos (2000): Los cientificos nazis en Argentina. Buenos Aires: Edhasa.

Oviedo, José Miguel (2005): "La literatura nazi en América de Roberto Bolaño". Letras libres, Noviembre: URL: <http://www.letraslibres.com/revista/libros/la-literatura-nazi-en-americade-roberto-bolano> (consultado el 4.12.2012).

Padilla, Ignacio (2000): Amphitryon. Madrid: Espasa Calpe.

- (2004): "McOndo y el Crack: dos experiencias grupales". In: Palabra de América. Guillermo Cabrera Infante (intr.). Barcelona: Seix Barral, 136-147.

Vasconcelos, José (1993): Indología. In: Leopoldo Zea [ed.], Fuentes de la cultura latinoamerica$n a$, t. I. México: FCE, 337-343.

VolpI, Jorge (2000): En busca de Klingsor. Barcelona: Seix Barral. 